\title{
LAKATOS Y FEYERABEND: UN ANTAGONISMO SOBRE EL DESAFIO DEL FALSACIONISMO POPPERIANO
}

\section{Lakatos and feyerabend: An Antagonism Around the Challenge of Popperian Falsabilism}

César Inca Mendoza Loyola*

Recepción: 08-01-2018

Aceptación: 18-05-2018

\section{RESUMEN}

Este artículo presenta el debate entre Imre Lakatos y Paul Feyerabend (amigos íntimos y, además, discípulos de Karl Popper) en torno al problema de cómo fundamentar el método científico. Se presenta, primeramente, a modo de introducción, la postura deductivista de Popper conocida como falsacionismo, la cual indica que la capacidad de las teorías científicas de someterse a la falsación a través de una actitud crítica con sus propios conceptos básicos. Luego, la postura epistemológica de Lakatos, conocida como Metodología de los programas de investigación, es explicada como una variante sofisticada del falsacionismo que en Popper comenzó con una versión ingenua. En las últimas dos secciones, el autor analiza la postura de Feyerabend - denominada por él mismo como Anarquismo metodológico - donde postula la tesis de que cualquier método es potencialmente válido para poner sobre el tapete de discusiones sobre los fundamentos metodológicos $y$ conceptuales en la ciencia.

\section{PALABRAS CLAVE}

Epistemólogo, deductivista, inductivista, racionalismo crítico, falsacionismo, anarquista, contrainducción, programas de investigación.

\begin{abstract}
This paper presents the debate between Imre Lakatos and Paul Feyerabend (close friends and also, disciples of Karl Popper) about the foundations of scientific method. First, as a sort of introduction, it presents Popper's deductivist position, known as falsification, which states the ability of scientific theories to submit to falsation through a critical approach to its own basic conceptions. Then, Lakatos' epistemological stance, known as the Methodology of Research Programs, is explained as a sophisticated version of falsification that started in a naïve fashion with Popper. In the last two sections, the author analyzes Feyerabend's position - which he himself baptized Methodological anarchism - whose main thesis is that any method is potentially valid in the set of discussions about the methodological and conceptual foundations of science.
\end{abstract}

* Docente de la Universidad Antonio Ruiz de Montoya. cesar.mendoza@uarm.pe 


\section{KEY WORDS}

Epistemologist, deductivist, inductivist, critical rationalism, falsifiability anarchist, counterinduction, research programs.

\section{INTRODUCCIÓN}

Tal como se anuncia en el título mismo, esta ponencia se centra en explicar el antagonismo de dos filósofos, Lakatos y Feyerabend, entrañables amigos personales y no menos entrañables rivales epistemológicos, en torno al siempre peliagudo tema de cómo fundamentar el saber científico como manifestación máxima del rigor de la racionalidad... e incluso ronda la posibilidad de negar que tamaña empresa sea inasequible, una posición que de hecho es sostenida por uno de los antagonistas que traemos a colación. La única manera de entender este antagonismo es revisar su raíz común, que es el modelo epistemológico falsacionista inaugurado por Popper (quien fue profesor de Lakatos y Feyerabend), pues el debate entre ellos dos se basa en las diferentes maneras que tuvieron de distanciarse de la huella popperiana, a la par que preservaban su inquietud deductivista, situándose así en oposición común al estándar inductivista propio de la concepción positivista de la ciencia. Karl Raimund Popper fue el pionero del así llamado falsacionismo (etiqueta que endilgaron a su filosofía de la ciencia y que el detestaba, pues él se veía a sí mismo simplemente como un racionalista crítico), la propuesta de que lo que caracteriza a las teorías científicas es su capacidad de someterse a la falsación a través de la contrastación de sus enunciados ante las evidencias empíricas. Esto supone que solamente la posición deductivista puede entender adecuadamente la armazón y la comprensión de las leyes y teorías científicas manejadas como conjeturas (o hipótesis) que funcionan desde el punto de partida del proceso de investigación.

\section{El falsacionismo como proyección del racionalismo epistemológico}

El falsacionismo postula con actitud asertiva que hay un proceso conceptual funcionando en nuestras mentes mientras observamos los fenómenos: ver un fenómeno no es solo mirarlo sino pensarlo mientras lo miramos, racionalizar los datos que causan un impacto físico en nuestras retinas por vía del estado interno de nuestro cerebro, el cual piensa a partir de expectativas, experiencias previas y conceptos aprendidos e internalizados (Chalmers 2005: 5-9). La lógica inductivista propia de las concepciones de ciencia manejadas por la corriente neopositivista y las modalidades empiristas de los siglos XIX y XX ostentan una errónea e inconveniente concepción meramente pasiva de la percepción sensorial, lo cual pone a nuestra capacidad intelectual de ordenar y conceptualizar nuestras experiencias en un rol secundario: según esta postura, nuestra capacidad de crear, conceptualizar y defender enunciados generales surge después de una influyente cantidad de experiencias sobre eventos particulares, pero "afirmar que la ciencia descansa sobre cierto conjunto de informes observacionales indubitables es, para Popper, hacer descansar a la ciencia sobre un fundamento nocientífico" (Brown 1998: 96). En realidad, "la observación es guiada por la teoría y la presupone", siendo así que "las teorías se construyen como conjeturas provisionales que el intelecto humano crea libremente en un intento de solucionar problemas con que tropezaron las teorías anteriores" y luego "han de ser comprobadas rigurosa e implacablemente por la observación y la experimentación" (Chalmers 2005: 57). Dicho de otra manera, "la ciencia no 
empieza con observaciones empíricas sino con problemas" dado que la mente del científico "no funciona como una tabula rasa provista de receptores sensoriales listos para registrar fielmente y sin interferencia de ninguna clase a la realidad, sino todo lo contrario" (Pérez Tamayo 2010:222). De este modo, en palabras de Lakatos, se anula la pretensión de poder observar los hechos con el "ojo desnudo" sin un esquema conceptual previo en nuestro intelecto, y se anula también la pretensión de que se puede llegar a conclusiones generales válidas a partir de la copiosa acumulación de casos particulares cuando, en realidad, el referente general ya está presente en el antes mencionado esquema conceptual. Esta propuesta resulta irresistible porque es un modelo de crítica científica que "contiene proposiciones empíricamente falsables que son espacio-temporalmente universales, sus condiciones iniciales y sus consecuencias", y portando como arma lógica al modus tollens," "ni la lógica inductiva ni la simplicidad intuitiva complican el panorama." (Lakatos 1987: 20-22)

Pero Popper no se limita a defender el rol primordial del enunciado general frente a la captación de eventos particulares, sino que además considera que la ciencia debe entenderse como un sistema de pensamiento que va en busca de falsaciones, es decir, que no se conforma con manejar casos que las confirmen y toparse con casos semejantes en el futuro inmediato, sino que asume una actitud autocrítica respecto a sus propias leyes y teorías. No hay nada más racional que aplicar sistemáticamente el método de ensayo y error donde las conjeturas (ya leyes comúnmente aceptadas, ya hipótesis novedosas) que maneja el investigador como idea-guía de su labor se abran al prospecto de desnudar sus errores y falencias hasta ahora insospechadas, ir en busca de falsaciones en vez de verificaciones (Richards 2000: 38). No hay un criterio de verdad operando aquí, pues no hay tal cosa como una certificación de la conquista de la verdad científica según el falsacionismo, sino un criterio de demarcación entre el discurso científico y el no-científico. El mismo Popper se niega a exigir "que un sistema científico pueda ser seleccionado, de una vez por siempre, en un sentido positivo, pero sí que sea susceptible de selección en un sentido negativo por medio de contrastes o pruebas empíricas; ha de ser posible refutar por la experiencia un sistema científico empírico" (1991: 40). El avance del saber científico sigue un curso infinito en el incesante descubrimiento de "problemas nuevos, más profundos y más generales" cuyas respuestas siempre provisionales se sujetan "a contrastaciones constantemente renovadas y cada vez más rigurosas" (Popper 1991: 261-262). Más bien, la óptica inductivista omite el carácter autocrítico de la racionalidad científica y no tiene suficientes armas para invalidar las propuestas de conjeturas ad hoc que se utilizan para seguir defendiendo una teoría cuya credibilidad está en franco declive: una conjetura es válida si se ofrece abiertamente a contrastarse frente a las evidencias empíricas mientras que la conjetura ad hoc (por tanto, pseudocientífica) sirve solamente al propósito político de defender un nicho conceptual por un interés ajeno al estrictamente científico.

Si el principio de verificabilidad propuesto por el neopositivismo señalaba que el significado de las proposiciones con sentido puede ser verificado por la observación, pronto se advertía que

1 Su estructura es: $\mathrm{p} \rightarrow \mathrm{q}$; - ; - $\mathrm{p}$. No tenemos $\mathrm{p}$ pues si tuviésemos $\mathrm{p}$, se habría tenido que dar q y no se dio éste. (Hurley, 2012: 362). 
dicho principio dejaba fuera muchas proposiciones científicas que aun no eran corroboradas por la experiencia. Para Popper, algo más adecuado sería proponer que las hipótesis deben ser planteadas por el científico con miras a su eventual negación. No se puede estar totalmente seguro de la validez de una teoría por mucho que vayamos acumulando casos confirmatorios; pero una vez que encontramos la excepción, queda claro que la teoría debe corregirse, o como sucede en muchos casos, negarse (Richards 2000: 38-39). La mente científica ha de proyectar sus ideas - una hipótesis, un sistema teórico, una propuesta de variante dentro del sistema teórico, lo que sea - sin una justificación previa pero con una plena disposición a que se extraigan conclusiones de ella por medio de una deducción lógica en base a enunciados empíricos basados en los datos experimentales o enunciados abstractos basados en estándares conceptuales de la teoría vigente (Popper 1991: 31 33), y si "durante el tiempo en que una teoría resiste contrastaciones exigentes y minuciosas, y en que no la deja anticuada otra teoría en la evolución del progreso científico, podemos decir que ha «demostrado su temple»" (Popper 1991: 33). Si lo que hace que un sistema científico sea riguroso es su capacidad de distinguir entre los enunciados que le son compatibles y los que le contradicen, tal rigor solo será factible bajo el criterio de falsación pues "los sistemas que no satisfacen la condición de falsabilidad no son capaces de efectuar discriminación entre dos enunciados cualesquiera que pertenezcan a la totalidad de todos los enunciados empíricos básicos posibles" (Popper 1991: 88).

Dar prioridad al falseamiento sobre la confirmación permite agilizar mucho las cosas en lo que concierne al robustecimiento de las leyes y teorías vigentes de las ciencias, y, de hecho, sustenta una lógica robusta para explicar el progreso del saber científico. Así, el modelo físico newtoniano era superior al de Kepler porque era más amplio al englobar un mayor número de factores en la explicación y se aplicaba a una mayor cantidad de fenómenos de interés científico (caída de los cuerpos, el movimiento del péndulo, etc.); lo mismo habría de pasar con el modelo einsteiniano ante el newtoniano (transformaciones mutuas entre masa y energía, nuevos datos sobre la velocidad y la trayectoria de la luz, etc.) (Chalmers 2005: 68-69). Pero ahora pongamos otro ejemplo, esta vez sobre el proceso de descubrimiento del planeta Neptuno ${ }^{2}$. Éste nació como problema científico porque las fórmulas matemáticas utilizadas para medir la órbita de Urano y que estaban basadas en ecuaciones del sistema newtoniano no se ajustaban a los datos empíricos recogidos en los observatorios, los cuales parecían mostrar una órbita irregular. Estamos en una situación de falsación, pero dicha situación no derribó el modelo newtoniano, sino que más bien motivó una solución provisional sujeta a una pronta verificación en los datos empíricos: resulta que hay un planeta más alejado que Urano dentro de nuestro Sistema Solar, y su presencia influye necesariamente en el modo en que se desarrolla la trayectoria de Urano alrededor del Sol. Esta solución momentánea se resolvió primero en el plano matemático, ajustando las ecuaciones con la introducción de la nueva variable y logrando definir una trayectoria regular para Urano; al poco tiempo, se descubrió empíricamente la presencia de ese nuevo planeta. Esto quiere decir que el criterio de falsación tiene que ser manejado con pulso y

2 Ejemplo de Lakatos en su La metodología de los programas de investigación científica (2010: 229-231) 
discreción, lo cual tiene sentido, pero a la vez, abre la puerta a la cuestión de cómo se puede limitar el espacio que divide entre el momento en que una solución provisional sigue siendo válida y otro en que no da para más. Es verdad que, con su sujeción práctica a la posibilidad de falsarse, la postulación matemática de un octavo planeta en nuestro Sistema Solar resultaba una idea atractiva y efectiva, pero este ejemplo pone sobre el tapete la exigencia de que haya algo más que falsación en la validación de las conjeturas y el manejo de los datos empíricos. Lakatos hará de esta exigencia el centro gravitante de su epistemología crítica.

\section{Una modalidad sofisticada de falsacionismo de la mano de Lakatos}

Imre Lakatos (nacido como Imre Lipschitz y luego rebautizado como Imre Molnár antes de pasarse a su nombre definitivo) carga sobre sus hombros la misión de crear una versión sofisticada de falsacionismo desde donde se pueda resolver la cuestión pendiente de cómo designar y decidir la validación de una falsación. Para ello, él debe recibir la herencia de su maestro mientras se distancia de ella relativamente al denominarla como falsacionismo metodológico ingenuo, remodelándola como falsacionismo metodológico sofisticado, aunque el nombre oficial de su propuesta es metodología de los programas de investigación. Lakatos hace un recuento histórico de la exigencia popperiana de la falsabilidad en la lógica científica, distinguiendo una primera fase de falsacionismo ingenuo que aparece expuesta en La lógica de la investigación científica y otra de falsacionismo sofisticado, con la cual halla fuertes confluencias, expuesta en conferencias y artículos desde mediados de los 60's (2010: 160-
174, 180-195). Desde el falsacionismo ingenuo, todo enunciado científico se pone a prueba como hipótesis frente a la posible emergencia de refutadores potenciales, o sea, un enunciado básico cuyo valor de verdad se sostiene sobre los alcances de las técnicas experimentales del momento. Así, un experimento controlado se repetirá varias veces en busca de la falsación mientras se determina el valor de verdad del refutador potencial: si éste es rechazado, la hipótesis es corroborada, o más exactamente, presta a ser atacada con adicionales estrategias falsacionistas en el futuro próximo, mas si es aceptado, la hipótesis queda refutada, "enterrada con honores militares" mientras se prepara la entronización de la nueva hipótesis que habrá de explicar en qué consiste ese fenómeno que había resultado misteriosa e inexplicable para la vieja hipótesis enterrada (Lakatos 2010: 184-185). Pero si bien esta propuesta establece el interesante e irresistible reto de caracterizar a la labor científica como esencialmente autocrítica y hábil controladora de sus propios desafíos, no se condice con el hecho bien certificado de que muchas teorías mantuvieron su vigencia a despecho de sus falsaciones persistentes. Por ejemplo, el perihelio de Mercurio era anómalo, pero ello no llevó a la anulación de la teoría newtoniana sobre las órbitas planetarias, y más bien los expertos archivaron el problema para considerarlo como un caso especial dentro del modelo aún aceptado (Lakatos 2010: 190). Así, dejar la propuesta del falsacionismo sin matices resulta contraproducente para la recta orientación racionalista y deductivista que se pretende para la epistemología.

Conservar el espíritu crítico y creativo de la idea falsacionista mientras se respeta el dinamismo reinante de las teorías científicas vigentes obliga a replantear 
el falsacionismo metodológico con una modalidad sofisticada donde se plantea que "el científico enumera anomalías, pero mientras su programa de investigación conserve su inercia, las ignora" (2010: 192). Éste es el leitmotiv de Lakatos. Para ello, concibe la actividad científica como un programa de investigación que contiene dos facetas claramente diferenciadas entre sí mientras que operan al unísono: una se llama núcleo central, la otra, cinturón protector. El núcleo central es la característica centralmente definitoria del programa de investigación y está conformada por las leyes más generales sobre las que se sostiene la teoría, mientras que el cinturón protector contiene hipótesis menos generales que funcionan como supuestos suplementarios de la teoría y cuya validez se admite mientras aún no han sido falseadas abrumadoramente por las evidencias empíricas (Chalmers 2005: 124-125). O sea, las teorías nacen ya falsadas, aunque disponen de un margen de maniobra para mantenerse saludables mientras lidian con las anomalías. Asimismo, hay dos tipos de labor científica que se corresponden con estas dos partes del programa de investigación: una se denomina heurística negativa, y sirve para designar una lista más o menos exhaustiva de problemas a evitar para no contradecir los principios básicos del antes mencionado núcleo; la otra es la heurística positiva y trabaja con las continuas modificaciones que tienen lugar en el cinturón protector mientras se resuelven problemas relativos al acomodo entre los datos empíricos y los contenidos teóricos del programa (p.e., afinamientos en las formulaciones de las leyes secundarias o el reemplazo de algunas que ya han sido falseadas por otras nuevas) (Richards 2000: 40-41). Tal como lo expresa el propio Lakatos, dentro de las reglas metodológicas propias de un programa, la heurística negativa se encarga de iniciar las rutas de investigación a ser evitadas mientras que la positiva nos señala los caminos que debe seguirse (Lakatos 2010: 52-53).

Ilustremos la doble dinámica de estas heurísticas con un ejemplo que Lakatos utiliza referente a la física newtoniana y el modelo astronómico implicado en ella, "si un planeta no se mueve exactamente como debiera, el científico newtoniano repasa sus conjeturas relativas a la refracción atmosférica, a la propagación de la luz a través de tormentas magnéticas y cientos de otras conjeturas, todas las cuales forman parte del programa. Incluso puede inventar un planeta hasta entonces desconocido y calcular su posición, masa y velocidad para explicar la anomalía" (2010: 8). Lejos de operar como una especie de "catecismo", la lógica de la heurística positiva obliga a la racionalidad científica a ser activa y creativa, desafiando varias de las ideas que sostiene en el presente mientras tiene como norte proteger con firmeza aquellas otras vías que conforman el centro neurálgico del programa: en efecto, pocos científicos se ocupan, según Lakatos, de las refutaciones que emergen en ocasiones y más bien "mantienen una política de investigación a largo plazo que anticipa esas refutaciones" en base a "un conjunto parcialmente estructurado de sugerencias o pistas sobre cómo cambiar y desarrollar las «versiones refutables» del programa de investigación, sobre cómo modificar y complicar el cinturón protector «refutable»" (2010: 55). Prácticamente es como si las teorías científicas ya nacieran como modelos de explicación cuestionables que, de todas maneras, tienen una manera sólida de guiar, organizar y enrumbar la labor de investigación científica. En palabras de Borge, "las leyes científicas son en sentido estricto falsas, pues refieren a estados ideales de cosas, o modelos que son 
abstracciones respecto de las realidades concretas que pretenden describir", pero no les es negada la validez pues ésta se puede obtener agregando "ciertas cualificaciones extras al enunciado original, que lo hacen aplicable a casos concretos." (2017: 156)

Si la heurística negativa ejerce un rol "institucional" en tanto que asegura la conceptualización, difusión y enseñanza del programa de investigación, entonces el rol de la heurística positiva es "ejecutivo", proactivo, director de estrategias para la supervivencia continuada del programa: en efecto, "un programa de investigación se dice que es progresivo mientras su desarrollo teórico anticipa su desarrollo empírico, esto es, mientras continúe prediciendo nuevos hechos con cierto éxito". El caso opuesto es el del programa degenerativo, aquél cuyo cinturón protector es incapaz de generar nuevas hipótesis y leyes secundarias a partir de los conceptos básicos del núcleo central mientras las anomalías (evidencias empíricas que contradicen dichos conceptos) se acumulan a un ritmo galopante: "si su crecimiento teórico se retrasa con relación al crecimiento empírico, esto es, si solo ofrece explicaciones post hoc de descubrimientos casuales o de hechos anticipados o descubiertos en el seno de un programa rival" (Lakatos 2011: 28-29. Lakatos 2011: 146-147).

De hecho, se podría decir que la actividad íntegra de la comunidad científica dentro de una rama específica está regida por una rivalidad continua entre diversos programas de investigación donde el predominante es el que da más indicios de actitud progresiva. La metodología de los programas de investigación adquiere su vitalidad en "la duradera rivalidad técnica y empírica de los principales programas de investigación, en los desplazamientos progresivos regresivos de problemática y en la victoria, que emerge lentamente, de un programa sobre otro" (Lakatos 2010: 127). Se ilustra esto con el ejemplo de Newton en la elaboración de la teoría cartesiana de los vórtices para demostrar que era inconsistente con las leyes de Kepler, y justamente este ejemplo le permite indicar que el trabajo del científico en medio de la necesaria rivalidad entre diferentes programas de investigación puede ser lo suficientemente dilatado para que resulte perfectamente racional trabajar en cualquiera de ellos (el futuro ganador y el futuro perdedor), o incluso en ambos simultáneamente. Así, "el progreso de un programa es un hecho vital para la degeneración de su rival" en tanto que "si el programa Pl produce constantemente hechos nuevos, éstos serán, por definición, anomalías con respecto al programa rival P2", y si éste solo explica estos hechos nuevos en base a argumentos ad hoc, "este programa está degenerando, por definición" (Lakatos 2010: 121, n. 37).

Esto nos lleva a preguntar a Lakatos cómo explica él la situación en que un programa de investigación llega a un estado de desgaste insostenible y debe ser reemplazado por otro programa que desde el punto de partida ostenta una saludable energía progresiva. ¿Cómo y cuándo se ha de dictaminar la irremediable superioridad de un programa sobre otro? Al fin y al cabo, en esto consisten los momentos más dramáticos del progreso de la ciencia, esos momentos donde lo que entendemos por conocimiento científico y metodología válidos se hallan severamente cuestionados y deben aclararse con la mayor premura posible. La clave está en ver cómo, dentro de la confrontación abierta entre varios programas de investigación, cuál de ellos puede predecir un fenómeno 
controvertido con más éxito que otro u otros, logrando simultáneamente explicar otros nuevos. Volvamos a exponer un ejemplo planteado por Lakatos, esta vez respecto a la agonía de la teoría del éter lumínico en inconsciente anticipación de la física einsteiniana.

Mientras que la mayoría de los físicos intentó interpretar los experimentos de Michelson y Morley en el marco del programa del éter, Einstein, desconocedor del trabajo de Michelson, Fitzgerald y Lorentz, pero estimulado fundamentalmente por la crítica de Mach a la mecánica newtoniana, llegó a un nuevo y progresivo programa de investigación. Este nuevo modelo no solo «predecía» y explicaba el resultado del experimento de Michelson-Morley, sino que también predecía un gran conjunto de hechos previamente insospechados que obtuvieron corroboraciones espectaculares. Solo entonces, veinticinco años después de que se produjera, consiguió el experimento de Michelson-Morley llegar a ser considerado «el máximo experimento negativo de la historia de la ciencia). (2010: 83) ${ }^{3}$

Así pues, los enunciados observacionales que se acumulan en el cinturón protector deben mantener una sostenida coherencia respecto a los enunciados teóricos que conforman el núcleo central a fin de que el programa en su conjunto permanezca progresivo; en el caso de un programa degenerativo, sus últimos manotazos de ahogado consistirían en crear enunciados observacionales hipotéticos de forma poco consistente para aún mantener algo de su actividad, pero este recurso no habrá de durar mucho. Estos enunciados observacionales poco consistentes son las conjeturas ad hoc que Popper también había opuesto a las conjeturas válidas (las dispuestas a falsearse ante las crecientes evidencias empíricas). De todas maneras, tengamos en cuenta que "el progreso de los programas científicos no implica la solución de todas las anomalías que lo aquejan pues siempre es conveniente recordar que estos se desarrollan en un océano de anomalías" (Toledo Nickels 1999: 7). Lo que sí tenemos en claro es que Lakatos ofrece un criterio de demarcación más sofisticado que el que brindaba el falsacionismo popperiano: en efecto, la ciencia opera con "una secuencia de teorías que se caracterizan por exhibir una continuidad reconocible que relaciona a sus miembros y permite identificarlos como versiones modificadas de un plan inicial común" (Toledo Nickels 1999: 4), mientras que un discurso pseudocientífico carece de este sentido del orden, inundándose de conjeturas y argumentos ad hoc por doquier.

Esta remodelación del estándar de la epistemología falsacionista con una arquitectura conceptual minuciosa donde cada estancia tiene su función y sus "muebles" propias, pero por muy tentador que suene todo esto, al menos en una primera impresión, no ha estado libre de críticas. Pérez Tamayo nos ofrece una buena síntesis de las objeciones recibidas por Lakatos desde varios ángulos:

Por ejemplo, no hay nada en el modelo de los programas de investigación científica que permita identificar a los componentes del núcleo central dentro de la

3 Lakatos cita este peculiar halago postrero al experimento de Michelson-Morley desde: BERNAL, J. D. (1965) Science in history. London: Watts. 
maraña de teorías que se manejan en un momento dado sobre un tema científico; tampoco es posible sostener que el núcleo central permanece inalterado, aun cuando el programa se encuentre en una etapa progresiva, pues en cualquier época uno o más investigadores pueden estar cuestionando alguna o algunas de sus partes fundamentales. Todavía más problemático resulta el cinturón heurístico positivo [...] por lo improbable de contar con una predicción razonable de las dificultades o anomalías que pueden surgir para las teorías del núcleo central. [...] Lo natural es que la respuesta a las anomalías, sea empírica o conceptual, surja después que ellas y no antes; de otro modo, se estaría invirtiendo recursos intelectuales de la manera más colosalmente ineficiente al intentar formular por adelantado la forma de responder a todas las anomalías teóricamente posibles. (2010: 228-229)

Parece que los malabares hermenéuticos que Lakatos realiza entre el optimismo epistemológico y el acento crítico propio de la mentalidad falsacionista para justificar su confianza en la concreción de un foco de certeza en la metodología científica desde la filosofía no funciona de todo: "las auténticas leyes solo pueden formularse mediante enunciados de longitud infinita y no son, por tanto, completamente cognoscibles para nosotros", lo cual habría de "derivar en un escepticismo epistémico respecto de las leyes, pero no es la conclusión que Lakatos está dispuesto a aceptar." (Borge 2017: 158) También Chalmers nos muestra sus objeciones a la precisión conceptual a la que Lakatos aspira con su modelo de programa de investigación: la utilidad del concepto de núcleo central queda muy en entredicho a la luz de eventos científicos tan significativos como el desplazamiento parcial del Sol hacia los centros de las órbitas planetarias y otros artificios de Copérnico diseñados "para ajustar los detalles del movimiento epicíclico hasta el punto en que dejaban de ser uniformes", o los intentos serios de la astronomía del siglo XIX por resolver las irregularidades percibidas del movimiento de Mercurio "modificando la ley de atracción del inverso de los cuadrados" (2005: 156 157). ¿Cuál es el núcleo central operante en estas actividades de investigación científica? ¿No sería más fácil ver en ellas sendas exhibiciones de iniciativas individuales relativamente motivadas por la efervescencia de ideas y debates científicos del momento? ¿No sería más consecuente ver en ellas una lógica basada en el deseo de creer en la veracidad de una ocurrencia propia y defenderla desde su propia "trinchera intelectual"? Preguntas así reflejan el tipo de inquietud epistemológica propia de la postura de Feyerabend, y justamente en él se centra la siguiente y última sección de esta ponencia.

\section{Frente al racionalismo... ianarquismo!}

Cuando Paul Karl Feyerabend entra en escena, lo hace decidido a plantear una novedosa y osada versión del poder de la razón científica para adueñarse de sus ideas y defenderlas según su fuerza de voluntad: su misión es entender a la razón científica liberándola de las ataduras del racionalismo, plantear una oposición diametral e incansable frente al racionalismo a partir de una postura que él usualmente denomina 
anarquismo epistemológico ${ }^{4}$. ¿Y cómo entiende Feyerabend a ese racionalismo al cual se opone con tanto fervor? Básicamente como toda la serie de intentos de "exponer un método científico capaz de captar su condición de especial", siendo así que el anarquismo epistemológico apuesta por el antirracionalismo "argumentando que no existe tal método y que, en realidad, la ciencia no posee ninguna característica que la haga necesariamente superior a otras formas de conocimiento" (Chalmers 2005: 142). O sea, Feyerabend quiere matar a dos pájaros de un solo tiro: 1) la pretensión de que existe algo así como una clave unitaria del saber científico, y; 2) la noción de que el mismo saber científico supone necesariamente una modalidad privilegiada de conocimiento. Esta última noción ha imperado consistentemente en la historia de la epistemología moderna ${ }^{5}$. Pero tal vez no se trata de dos pájaros distintos sino de dos caras de una misma moneda, pues la búsqueda filosófica de aquel método único de la ciencia históricamente ha sido motivada por la idea de que la mente puede mirarse a sí misma y descubrir la manera sistemática de explotar su excelencia: la mathesis universalis cartesiana y su ulterior versión ecléctica leibniziana, el esquema kantiano de las condiciones a priori de la sensibilidad y el entendimiento, la vía imparable hacia la instauración del estado positivo de la cultura desde la muy optimista epistemología comtiana, todos ellos son ejemplos de auto-inspecciones de la racionalidad "en su máxima gloria".
Según Feyerabend, cada vez que un paradigma científico se vuelve sumamente importante para una vasta mayoría de investigadores de una determinada rama, la filosofía de la ciencia hace una reconstrucción lógica de los fundamentos del nuevo saber "oficial" de la ciencia.

El problema de este enfoque es que las formulaciones reconstruidas son en su mayor parte estériles: no tienen el poder de sugerir acciones, ideas o procedimientos nuevos. Solo las desconcertantes declaraciones de los científicos parecen tener ese poder. Lo cual significa o que no puede haber descubrimientos a menos que se abandone la casa de la razón o que la casa de la razón es muy diferente de cómo nos la han pintado los filósofos y otros traficantes de ideas. (Feyerabend 1999: 152)

La remodelación lakatosiana de la propuesta falsacionista de Popper le parece a Feyerabend la muestra más acabada de esta vertiente epistemológica, y, justamente por ello, hay que ponerla en la mira principal del ataque antirracionalista. Frente a la ambición arquitectónica del concepto de programa de investigación, Feyerabend propone la alternativa de la soltura traviesa e iconoclasta de la contrainducción, concepto clave para focalizar nuestra comprensión del antirracionalismo feyerabendiano. La forma más casual de expresar la dinámica de la contrainducción es "itodo vale!", pero para ponernos más sistemáticos,

4 Bien es verdad que en un pasaje del cap. 2 de su Tratado contra el método, él prefiere la expresión dadaísmo epistemológico en tanto que el concepto de Dada no solo se niega a conformar un programa, sino que se opone a todos los programas habidos y por haber (respecto a esto cita al libro de Hans Richter Dada: Arte y anti-arte). Así, evita del todo repetir la "institucionalización" del anarquismo como un modelo fijo de pensamiento dentro de le evolución de la teoría política contemporánea.

5 Severino expresa bellamente el balance general de la filosofía cartesiana, centrada en la fundamentación de la ciencia: "La «verdadera y cierta ciencia» no comprende sólo los aspectos cuantitativos de la realidad como se presentan en la abstracción de los conocimientos matemáticos, o sea, como esencias inmutables y eternas: comprende también los aspectos cuantitativos de la realidad que aparecen clara y distintamente como cualidades de los cuerpos: extensión, figuras, números, movimientos. Matemática y física pertenecen al árbol de la episteme." (1986: 69-70). 
diremos que ella funciona con dos reglas básicas $\left.{ }^{6}: 1\right)$ desarrollo de hipótesis inconsistentes con las teorías aceptadas; 2) desarrollo de hipótesis inconsistentes con hechos bien establecidos.

Feyerabend tiene a las objeciones de Galileo contra la concepción estacionaria de la Tierra y contra la invariabilidad de los tamaños de Venus y Marte a lo largo del año como ejemplos favoritos de aplicación de estas dos reglas. Empezando con la primera de estas objeciones, Galileo debía explicar por qué una piedra arrojada desde la cima de una torre caerá a los pies de ésta y no un poco más lejos, por lo que tuvo que "estrujar el cerebro" de sus interlocutores (lectores y oyentes) para persuadirles de que acepten que la velocidad de una bola que rueda por una pendiente sin rozamiento aumentará en tanto que se orienta hacia el centro de la Tierra, disminuirá si rueda en una pendiente hacia arriba sin rozamiento y que ni aumentará ni disminuirá al moverse por una pendiente horizontal. Respecto a la cuestión de los tamaños de Venus y Marte, tuvo que sugerir el reemplazo del testimonio a simple vista por el de un "ojo mejorado", el telescopio. Como Galileo no contaba con una teoría adecuada para interpretar los datos objetivos que del lente - diseñado, al fin y al cabo, para distorsionar lo visible - tenía que recurrir a argumentos rebuscados para "estrujar el cerebro" y hacerles aceptar sus interpretaciones de los datos telescópicos (Chalmers 2005: 143-145). Y es aquî donde se nos muestra claramente que la validación "oficial" de las propuestas de interpretación científica - especialmente las novedosas, que son las que mejor reactivan el saber científico - proviene principalmente de la persuasión, eso que varias veces denomina el propio Feyerabend como "estrujar el cerebro". Si la contrainducción debe ir contracorriente de las teorías predominantes y de los experimentos estandarizados, entonces sus resultados solo serán exitosamente recibidos por la comunidad científica (o al menos, una fracción importante de ella) si es que se elabora acuciosas e impetuosas "invitaciones" a seguir este camino contracorriente de parte del impulsor de la nueva idea. ${ }^{7}$

Una consecuencia directa de lo que se proyecta desde este eslogan de "todo vale" es que se alienta sin mayores exigencias de consistencia conceptual sobre una base de principios universalmente aceptados por la comunidad de expertos es la propuesta de un principio de proliferación como alternativa al falsacionismo metodológico ingenuo popperiano sobre el que se había iniciado este debate. Se trata de la recomendación de invención de diversas hipótesis de trabajo en el trabajo de campo científico y propuestas de teorías alternativas a los paradigmas mayoritariamente sancionados - cuanto más diversas, mejor - de tal modo que la labor de investigación se dinamice y se evite la eliminación de teorías más antiguas que se supone ya eliminadas del horizonte hermenéutico científico. Feyerabend reconoce en ello una fuerte coincidencia con Lakatos, quien indicó que las teorías científicas alternativas no son meros

6 A Feyerabend le gusta denominarlas contrarreglas, como lo hace en varios pasajes de su Tratado contra el método. Pero, ¿qué es la contrainducción sino una propuesta de sistematización de la lógica deductivista sin más ni más?

7 Gargiulo señala algunos ejemplos de textos de epistemología donde se objeta el modo en que Feyerabend malinterpretó y distorsionó la calidad y la evolución de los conocimientos de óptica de Galileo, y de paso, se le tacha de irracionalista y un enemigo de la ciencia. Éstos son: Theocharis, T., Mihalis, P., (1987), "Where Science Has Gone Wrong," Nature 329, 595-598. / Bunge, M. (2003). Cápsulas. Barcelona: Gedisa. / Horgan, J. (1993) "Paul Karl Feyerabend: El peor enemigo de la ciencia", Investigación y Ciencia 201, 34-48. (2014: 55, n. 7) 
catalizadores que pueden eliminarse en la reconstrucción racional del progreso del saber científico, pero le acusa de atribuirle una concepción meramente psicologista de esta apreciación mientras se atribuye a él mismos sus puntos de vista (1997: 32, n. 35). ${ }^{8}$ De hecho, él añade: "Mi disputa con Lakatos se refiere a los criterios que él recomienda, a su evaluación de la ciencia moderna (en comparación con, por ejemplo, el mito o la ciencia aristotélica), a su pretensión de haber procedido «racionalmente», así como a los datos históricos particulares que emplea en su discusión de las metodologías" (1997: 171).

Otra consecuencia directa de la dinámica del "todo vale" es que no hay manera de sustentar el nexo entre dos modelos o paradigmas científicos, no hay manera de hacer traducible una forma de pensar motivada desde la fuerza de voluntad específica de un observador científico al lenguaje de otra forma de pensar que se sustenta sobre otros intereses. Coincidiendo con Kuhn y discrepando con la muy difundida óptica empirista, no hay solución de continuidad entre la teoría de la relatividad einsteiniana y la mecánica newtoniana, por mucho que las ecuaciones de esta última puedan verificarse para condiciones de baja velocidad de acuerdo a los criterios de la primera, pues esta compatibilidad en las formalidades operacionales no genera precisamente ecuaciones newtonianas sino otras concebidas bajo una óptica post-newtoniana sobre el orden del universo físico (Brown 1998: 159). ${ }^{9}$ Otra consecuencia es que se disuelve la distinción entre conjeturas válidas y ad hoc, pues dentro de este escenario anarquista, todas las conjeturas propuestas para llenar huecos de una teoría y defenderla de las evidencias supuestamente contrarias resultan ser ad hoc. Los nuevos puntos de vista que entran a tallar en el campo de la ciencia teniendo como puntos de referencia a las teorías anteriores, como fue el caso de Galileo, "intentan acomodar su núcleo factual con la ayuda de hipótesis ad hoc, aproximaciones ad hoc, redefiniciones de términos, o afirmando simplemente, sin un estudio detallado de la cuestión, que dicho núcleo «se sigue de» nuevos principios básicos" (Feyerabend 1997: 163). ${ }^{10}$ Y de hecho, no son algo así como "males necesarios" o algo a lo que recurrimos porque no hay nada mejor a nuestra disposición: todo lo contrario, "las hipótesis y las aproximaciones ad hoc crean un área tentativa de contacto entre los «hechos» y aquellas partes del nuevo punto de vista que parecen capaces de explicarlos, alguna vez en el futuro y tras la adición de mucho más material" (1997: 165).

En todo evento de contrainducción se fusionan el acto de ver y el acto de pensar lo que se ve: "Eliminad parte del conocimiento teórico de un sujeto inteligente, y tendréis una persona completamente desorientada e incapaz de realizar la acción más simple. Eliminad

8 Feyerabend cita su propio artículo "Reply to criticism" (Boston Studies, vol. II, 1965) y a Lakatos (201 1: 24, n. 27)

9 Brown cita a Feyerabend en su aporte "Problems of empiricism" dentro del libro: COLODNY, Robert (1965) Beyond the edge of certainty. New Jersey: Prentice-Hall.

10 "Las aproximaciones ad hoc abundan en la física matemática moderna. Desempeñan un papel muy importante en la teoría cuántica de campos y constituyen un ingrediente esencial del principio de correspondencia: las aproximaciones ad hoc ocultan, incluso eliminan por completo las dificultades cualitativas. [...] Se sigue de ello que un filósofo que quiera estudiar la adecuación de la ciencia en cuanto representación del mundo o que quiera construir una metodología científica realista ha de examinar la ciencia moderna con una cautela muy especial" (Feyerabend 1997: 47). 
más conocimiento y su mundo sensorial (su «lenguaje observacional») empezará a desintegrarse, desaparecerán los colores y otras sensaciones simples hasta llegar a un estado más primitivo que el que tiene un niño" (Feyerabend 1997: 155). La experiencia como evento científico se da al unísono de la aclaración y asunción de las suposiciones teóricas, por lo que la distinción entre enunciados observacionales y enunciados teóricos termina revelándose como muy trivial: en efecto, enunciar que la causa del efecto A es $B$ o que hay una relación de contigüidad entre el evento A y el evento B implica necesariamente el haber aprendido a ver a B como el causante del A que se muestra ante nosotros o el asumir instantáneamente que A está junto a B aunque en este momento solo estemos percibiendo la presencia del segundo. Y justamente por ello se realza el papel rector del pensamiento a la hora de darse el acto de percibir, siendo así que aquél puede brindarle a éste una mayor claridad e visión si es que no se deja moldear (o se deja moldear lo menos posible) por los principios de los paradigmas vigentes. En una de tantas expresiones entusiastas de Feyerabend nos indica lo siguiente: "iLas cosas más sorprendentes conducen a los grandes descubrimientos! Los que creen que solo puede descubrirse cosas nuevas recorriendo una trayectoria definida precisamente están equivocados. No se puede prever el tipo de paso tonto que llevará a una nueva idea o a un nuevo descubrimiento. El paso es «tonto» solo si se lo compara con la opinión general de la época" (1999: 157). Si el epistemólogo acepta que existen condicionamientos teórico-culturales previos al acto de percibir y éstos se fundamentan en el paradigma en que el observador fue educado, se sigue de ahí que aún los enunciados observacionales son, en esencia, teóricos (Toledo Nickels 1998: 19).
Dado que la vitalidad y el progreso del conocimiento científico se basan esencialmente en las vicisitudes exitosas de las irrupciones contra corriente de iniciativas individuales que ganan adeptos hasta el punto de convertirse en paradigmas dominantes del momento, tenemos entonces que la pretensión de toda filosofía racionalista - exégesis de la racionalidad científica sobre los fundamentos fijos sobre los que sostiene la maximización de su capacidad de saber - ha resultado un fracaso continuado donde la cándida terquedad y las buenas intenciones no han dado réditos suficientes. Todas sus tentativas han terminado cayendo en un saco roto y, por lo tanto, solo cabe concluir "que no se justifica el elevado rango atribuido a la ciencia en nuestra sociedad" y que "el alto prestigio de la ciencia es un dogma peligroso" (Chalmers 2005: 146 147). Pero, claro, este alto prestigio de la ciencia se debe a una concepción errónea de la misma: no se trata de un modo de pensamiento focalizado hacia lo que se aspira que en algún tiempo futuro sea un monolítico esquema sistematizado de teorías y recolecciones de datos empíricos. Por el contrario, "la ciencia es un continente de muchas opiniones, procedimientos, «hechos», «principios». No es una unidad coherente. Diversas escuelas dentro de una misma disciplina (tendencias empíricas y teóricas en la astrofísica, la cosmología y la hidrodinámica; la fenomenología y la «gran teoría» en la física de las partículas elementales, etc.) emplean procedimientos que difieren mucho entre sí, tienen diferentes visiones del mundo, debate sobre ellas y tienen resultados: la naturaleza parece responder positivamente a muchos enfoques, no a uno solo." (Feyerabend 2001: 250). He aquí el precio que paga gustoso Feyerabend para la autorización de su 
lema "itodo vale!": rechazar la idea de un proceder uniforme en la ciencia y otorgar al investigador la más amplia libertad metodológica, negar autoridad a la dictadura del monismo metodológico y postular la proliferación de métodos y teorías alternativas equivalentes (Toledo Nickels 1998: 10). Feyerabend quiere decir adiós a una racionalidad bosquejada en términos monistas para dar la bienvenida a otra de talante pluralista... o, mejor dicho, motivarnos a admitir de una vez por todas que nunca fue monista.

\section{El anarquismo como una especie de legado popperiano}

Insistiendo en este detalle particular, Feyerabend saca a colación, como ejemplo ilustrativo, una pregunta que se hace Einstein en una de sus cartas: "¿No resulta verdaderamente extraño que los seres humanos sean sordos por lo general al argumento más sólido, mientras que se muestran siempre propensos a sobrestimar la exactitud mensurable?" Justamente es esta sobrestimación la que, según Feyerabend, instaura las normas de funcionamiento de las investigaciones de epidemiología, genética, espectroscopia y otras disciplinas, así como las de las ciencias sociales (2001: 178-180). ${ }^{11}$ Asî pues, "no existe la «visión científica» del mundo del mismo modo que la «ciencia» no es una empresa uniforme, excepto en las mentes de los metafísicos y científicos cegados por los éxitos de su propio gremio particular" (2001: 190). Al fin y al cabo, el pleito que tiene este anarquista no es con los científicos comprometidos con las labores concretas de investigación sino con los instrumentos lógicos que muchos científicos y filósofos epistemólogos pretenden desarrollar para cumplir con el objetivo de marcar una pauta del saber científico como un bloque ordenado, y más bien lo que se da es un conglomerado de paradigmas diversos e inconmensurables en medio de las cuales se aspira a conocer un poco más que ayer los eventos naturales (Pérez Tamayo 2010: 247-248). Esta libertad creativa que usualmente asociamos exclusivamente al campo del arte puede ser también el mecanismo para motivar el surgimiento y auge de nuevas verdades científicas. Esto refuerza la consigna feyerabendiana de que "la naturaleza parece responder positivamente a muchos enfoques y no a uno solo", mas nada de esto conlleva un relativismo propiamente dicho: para el pensador austriaco, es natural que no todas las aproximaciones a eso que llamamos realidad tengan éxito o cuenten con un éxito a corto plazo, y es que esa "realidad última" nunca se nos muestra como tal: "lo que conocemos son las diversas formas de la realidad manifiesta, es decir, las formas complejas en que la realidad última actúa en el dominio de la vida humana." (Feyerabend 2001: 253) Ante lo aquí expuesto, hay que aceptar que estas interacciones entre las manifestaciones de la realidad y nuestras formas de captarlas y pensarlas se expresan, proponen, discuten e imponen en redes conceptuales, juegos de lenguaje donde se expresan cosmovisiones que, en tanto entidades cerradas, admiten e instituyen percepciones y pensamientos sobre lo que existe, simultáneamente excluyendo los que pretenden remitirse a lo que no existe. (Feyerabend 2001: 55)

Tenemos aquí la apuesta por la noción de paradigma y la apuesta por la inconmensurabilidad entre paradigmas que Feyerabend toma prestado de su amigo Thomas Kuhn. ${ }^{12}$ Pero si Kuhn propuso una epistemología en base a la

11 Feyerabend se remite al libro: BORN, Max (1971) The Born-Einstein Letters. Nueva York: Walter. 12 Véase: KUHN, T. S. (2004) La estructura de las revoluciones científicas. México: F.C.E., capx. IV-X. 
inconmensurabilidad entre paradigmas para hacer una hermenéutica sociológica del comportamiento de la comunidad científica en los eventos previos a la instauración de una nueva teoría tras la resolución de una revolución científica, Feyerabend se propone remodelar este término para designar la "esencia" misma del pensamiento, eso que por siglos y siglos hemos denominado como logos desde aquellos lejanos tiempos de los pioneros de la filosofía antigua griega. Tal como señala Gargiulo, Feyerabend "no se limita a aplicar su noción de inconmensurabilidad a los conceptos y a las teorías, sino que la extiende también a la relación que puede existir entre cosmovisiones, tradiciones, culturas, comunidades, paradigmas, valores, prácticas, acciones, percepciones, cuestiones, problemas, etc." ${ }^{13}$ (2016: 62) Así pues, la vitalidad conceptual que continuamente vibra con racionalizaciones sobre los datos que percibimos no es tan solo una forma de "dogmatismo", esa herramienta de cuestionamiento frente al falsacionismo ingenuo de Popper. No, es más que eso, es el acto de mirarse detenidamente al espejo que realiza la propia racionalidad: ella no puede evitar fijar un entramado de conceptos, definiciones y pautas hermenéuticas, pero algo que no hace muy a menudo, a pesar de que también se sabe capaz de hacerlo, es cuestionarse sobre el camino y enfrentar la siempre viable, pero, a la vez, inesperada posibilidad de cambiar sus bases ontológicas y ver a un mundo nuevo trazado y concebido con un nuevo paradigma. ¿No podría ser esto una capitalización radical del modelo falsacionista de Popper? La propuesta de una razón que se abra continua y consistentemente a las siempre abiertas posibilidades de crisis de paradigmas y cambios de concepciones sobre la realidad dice adiós a la razón. No existe, a los ojos de Feyerabend, posibilidad alguna de desentrañara la única y monolítica manera de encapsular el desarrollo histórico de los éxitos del pensamiento teórico y, con él, el método común para las soluciones a las crisis que se han desarrollado a lo largo de esa historia con resultados concluyentes. ¿Por qué?

Porque el resultado depende de condiciones que son, en parte, "objetivas" (por ejemplo, propiedades de los materiales), pero que también contienen un amplio componente "subjetivo" (por ejemplo, el temperamento de un participante). Ambas condiciones pueden permanecer estables durante largos períodos de tiempo, pero la estabilidad de las relaciones abstractas causadas por ello no muestra que hayamos encontrado por fin la naturaleza de la Razón Científica: solo muestra que el espíritu del mundo a veces duerme. (Feyerabend 2015: 71 72)

Entonces, lo que pone Feyerabend como oposición al falsacionismo sofisticado de Lakatos no es tanto una recusación del modelo epistemológico falsacionista per se (aunque algo de eso hay, sin duda) sino el impulso de una radicalización de la esencia crítica de todas sus modalidades de razón con sus consecuentes concepciones de saber, verdad, objetividad y ciencia. Un ultrafalsacionismo, si se quiere. Feyerabend nos invita, con su retórica, traviesa y candorosa a la vez, revestida de soflamas y alocuciones vorazmente provocativas, a que la misma racionalidad humana está continuamente sujeta al cuestionamiento de símisma mientras desarrolla paradigmas

13 Ella se basa en el libro: OBERHEIM E. (2006) Feyerabend's Philosophy. Quellen Und Studien Zur Philosophie. Berlín: Walter de Gruyter. 
y modelos de pensamiento que, a lo largo de la historia, van sucediéndose con la pretensión de haber evolucionado de algún modo y haber superado errores y baches pasados. Esta "manera radical de falsacionismo" impone un adiós a la razón en nombre de una bienvenida a la pluralidad de racionalidades... al menos, en el debate de propuestas alternativas con las cuales se pueda crear algún tipo de progreso en el saber. Cedemos nuevamente la palabra a Gargiulo cuando afirma que la obra de Feyerabend no puede ser catalogada como simplemente destructiva y relativista pues también se preocupa por proponer "positivamente un modelo de ciencia alternativo a aquellos que son objeto de sus diatribas y denuncias", con lo cual, "su doctrina de la inconmensurabilidad, su pluralismo teórico y su anarquismo epistemológico, pueden ser leídos y analizados efectivamente como reducciones al absurdo de las nociones tradicionales de ciencia de aquel entonces" (2017: 212) y que aún siguen vigentes en el pensamiento colectivo de la academia científica.

Centrándonos en la racionalidad que vive y transpira a través de las labores de investigación teorización y trabajo de campo científicos, Feyerabend aprecia en cualquier observación detenida de la secuencia de sucesiones de paradigmas predominantes en las diversas ramas de la ciencia la constatación de que una ciencia fidedignamente interesada en la verdad "debe retener todas las ideas de la humanidad para su posible uso" pues "la historia de las ideas es un constitutivo esencial de la investigación científica." (2015: 110 - las cursivas son del propio autor) De hecho, la inmensidad cuantitativa de todas esas ideas gestadas por la humanidad es tan grande que no hay programa colectivo ni genio individual que pueda lidiar con tan abrumador bagaje conceptual que hereda, ya sea que lo sepa o no, de su tradición. Desde la investigación científica hay que seleccionar enfoques de interpretación de los datos a partir de elecciones tentativas cuyas aceptaciones implican que hay otro cúmulo de sugerencias alternativas que no se han evaluado con suficiente meticulosidad (2001: 112-114). El estándar objetivista no tiene razón de ser ante la constatación de cómo la exorbitante inmensidad del mundo ha sorprendido a los aparatos conceptuales de la mente humana; por su parte, el estándar relativista olvida que la postulación y desarrollo de los paradigmas implican un compromiso serio de parte de la mente humana con una ontología sin la cual no podría funcionar. No es irracionalismo ni relativismo lo que late y palpita en el anarquismo epistemológico de Feyerabend, sino que es una defensa de la abundancia del mundo (o si lo preferimos llamar así, la realidad) como eje filosófico para una epistemología perpetuamente crítica de sí misma, no solo de sus paradigmas dominantes del momento sino también de su propio modus operandi cuando hace lo que siempre hace, confrontarse y comprometerse con el ser en el que cree.

Para el objetivismo, la naturaleza de las cosas puede determinarse en virtud de un marco permanente, universal y a-histórico de pensamiento. Para el relativismo, en cambio, todos los conceptos o sistemas de pensamiento son relativos a un marco sociohistórico determinado. Feyerabend con su metafísica de la abundancia procura elaborar una ontología que trascienda o abandone estas dialécticas relativismo/absolutismo propias de la epistemología moderna. Se esfuerza por mostrar que ni el objetivismo ni el 
relativismo pueden dar razón de la comunicación e interacción entre las culturas, ni de la abundancia de lo real. (Gargiulo 2017: 216)

Así, la propuesta de Feyerabend se revela como una celebración entusiasta, incluso exacerbada hasta extremos casi dadaístas ${ }^{14}$, de la vitalidad crítica que la razón, diversa y siempre abierta a mayores diversificaciones internas con el transcurso de la historia, ha elaborado a lo largo de la historia de la ciencia. Se trata de una diversidad donde el fantasma de la falsación visita cada rincón de los conceptos fundamentales de cada paradigma en juego, ya sea vigente o emergente.

\section{Conclusión}

Llegamos al balance final de este modesto repaso que hemos hecho del debate entre Lakatos y Feyerabend. Hemos visto cómo ambos asumen concienzudamente el legado de la epistemología crítica popperiana y cómo sus maneras de remodelar este legado los llevan a orillas opuestas: mientras que Lakatos detecta áreas ingenuas del falsacionisno original y se aboca a una nueva reconstrucción de la racionalidad científica con miras a madurar dicho falsacionismo hacia una expresión más sofisticada, Feyerabend lleva la crítica hasta el radical cuestionamiento de la capacidad de la racionalidad científica para expresarse en leyes o métodos generales, dudando de que la racionalidad científica como tal exista (Toledo Nickels 1998: 17). Las alternativas son claras y están bien dispuestas a ser recibidas por quienes quieran creer en la potestad de la razón para darse un método a sí misma en base a ciertas reglas que pretenden legitimar el acceso al conocimiento válido, así como para quienes prefieren ver en la razón el campo más amplio para la expresión libre de nuestras inquietudes, todas ellas potencialmente válidas desde el punto de partida. Y ese punto de partida no es sino la apasionada fuerza de voluntad de un sujeto erudito que quiere impugnar el estándar dominante de que " $e l$ orden del mundo es así" y poner propuestas alternativas sobre el tapete de los debates internos de la investigación científica, debates que, por su propia naturaleza crítica, deberían conformar la esencia más genuina de su método gnoseológico. Si Lakatos fue el discípulo de Popper que aspiró a remodelar la arquitectura de la objetividad científica desde los patrones de criticismo iniciados por su susodicho maestro, Feyerabend fue el oponente a cualquier concepción monolítica de racionalidad, convirtiéndose así en el más leal acólito de la dinámica de la falsación.

\section{Referencias bibliográficas}

\section{Fuentes primarias.}

\section{FEYERABEND, P. K.}

2015 Adiós a la razón. Madrid: Tecnos.

2001 La conquista de la abundancia. Paidós: Barcelona.

1999 Ambigüedad y armonía. Paidós: Barcelona.

14 El propio Feyerabend reconoce en una nota a pie de su clásico Tratado contra el método que la etiqueta de anarquismo epistemológico que él mismo creó fue utilizada de una manera casi aleatoria, más que nada, pensando en su repulsión de un régimen racional único para la ciencia. Pero, teniendo en cuenta que, en las dimensiones éticas y políticas, se han dado brotes de pensamiento puritanos y fundamentalistas que él detesta, preferiría más bien la etiqueta de dadaísta pues "un Dadaísta está convencido de que una vida que merezca la pena sólo será factible cuando empecemos a tomar las cosas a la ligera y cuando eliminemos del lenguaje aquellos-significados profundos, pero ya putrefactos que ha ido acumulando a lo largo de los siglos." (1997: 6, n. 12) 
1997 Tratado contra el método. Madrid: Tecnos.

LAKATOS, I.

2011 Historia de la ciencia y sus reconstrucciones racionales. Madrid: Tecnos.

2010 La metodología de los programas de investigación científica. Madrid: Alianza Editorial.

\section{Fuentes secundarias.}

BORGE, B. (2017). Verdad y leyes de la naturaleza en la metodología de los programas de investigación científica. En: Signos Filosóficos, Vol. XIX, No. 37, enero-junio 2017, pp. 146-169.

BROWN, H. (1998). La nueva filosofía de la ciencia. Madrid: Tecnos.

CHALMERS, A. (2005). ¿Qué es esa cosa llamada ciencia? Madrid: Siglo XXI.

GARGIULO, T.

2017 Feyerabend ¿Un filósofo de la ciencia posmoderno? En: Anales del Seminario de Historia de la Filosofía, 34 (1), pp. 203-227.

2016 La doctrina de la inconmensurabilidad en Paul Feyerabend: una objeción contra una particular concepción de racionalidad científica. En Areté. Revista de Filosofía, Vol. XXVIII, No. 1, 2016, pp. 61-87.

2014 El caso Galileo o las paradojas de una racionalidad científica positivista según Paul Karl Feyerabend. En: Tópicos. Revista de Filosofía, No. 47 (2014), pp. 53-88.

HURLEY, P. (2012). A concise introduction to logic. Wadsworth: Cengage Learning.

KUHN, T. S. (2004). La estructura de las revoluciones científicas. México: F.C.E.
PÉREZ TAMAYO, R. (2010). ¿Existe el método científico? México: SEP / FCE. POPPER, K.

2010 Conocimiento objetivo. Madrid: Tecnos.

1991 La lógica de la investigación científica. México: Rei.

RICHARDS, S. (2000). Filosofía y sociología de la ciencia. México: Siglo XXI.

SEVERINO, E. (1986). La filosofía moderna. Barcelona: Ariel.

TOLEDO NICKELS, U. (1999). Ciencia y pseudociencia en Lakatos. En: Cinta de Moebio, No. 5, 1999. Universidad de Chile, pp. 1 13. Consulta: mayo de 2018.

< http://www.redaly c.org/ pdf/101/10100507.pdf $>$

1998 La epistemología según Feyerabend. En: Cinta de Moebio, No. 4, 1998. Universidad de Chile, pp.1-26. Consulta: mayo del 2018.

$<$ h t t p: // w w w.redaly c. or g / pdf/101/10100402.pdf $>$

TOLEDO NICKELS, U.

1999. Ciencia y pseudociencia en Lakatos. En Cinta de Moebio, No. 5, 1999. Universidad de Chile, pp. 1-13. Consulta: setiembre de 2017.

< http://www.redaly c.org / pdf/101/10100507.pdf $>$

1998 La epistemología según Feyerabend. En: Cinta de Moebio, No. 4, 1998. Universidad de Chile, pp. 1-26. Consulta: setiembre de 2017.

< h t t p : / / w w w.redaly c.org / pdf/101/10100402.pdf 